\title{
Identification of factors affecting infant growth in developing countries
}

\author{
M P ECCLES, ${ }^{*}$ T J COLE, $\dagger$ AND R G WHITEHEAD $\dagger$ \\ Medical Research Council Dunn Nutrition Unit, *Keneba, The Gambia, and †Cambridge
}

SUMmARY The anthropometric progress of seven infants was followed throughout their first year of life. Weight, length, mid upper arm circumference, triceps and subscapular skinfold thicknesses were measured on a mean (SD) of $30(6)$ occasions with weight alone being measured on a further $6(2)$ occasions. The effects of infection and energy intake were identified and illustrated using both standard deviation (SD) score graphs for individual subjects, and more traditionally, regression analysis for the group. Diarrhoea and vomiting, pneumonia, and diarrhoea alone each resulted in significant reductions in growth velocity of $30 \mathrm{~g} / \mathrm{day}$. Multimeasurement SD score graphs showed the effects of all illnesses, and permitted simultaneous comparison of anthropometric measurements.

The effect of acute infection on growth has been widely studied, predominantly in third world countries. In Mexico ${ }^{1}$ and Guatemala ${ }^{2}$ the infective causes of weight loss were diarrhoea, dysentery, and bronchopneumonia. In rural Gambia they were gastroenteritis and malaria, ${ }^{34}$ and in Uganda they were gastroenteritis and measles. ${ }^{4} \mathrm{~A}$ recent study from urban Gambia again identified diarrhoea and also lower respiratory tract infection. ${ }^{5}$

Such studies have traditionally relied upon mean weight deficit calculated by regression analysis to quantify the effects of infection, showing reductions in weight gain of as much as $746 \mathrm{~g} /$ month $^{3}$ or $22 \mathrm{~g} /$ day for the various infections. ${ }^{5}$

An alternative approach is to express weight, and any other available anthropometric measurements, as standard deviation (SD) scores adjusted for age. The graphical presentation of such information has, however, always been limited by an inability to provide a comprehensive anthropometric picture of an individual subject without recourse to five or six separate centile charts.

There is also the question of the appropriateness of the standards used. In adopting the National Center for Health Statistics (NCHS) growth curves ${ }^{6}$ as their international standard, the World Health Organisation (WHO) defined their standards for body weight, length, and head circumference. ${ }^{7}$ The values that they chose for mid upper arm circumference were based on the data of Wolanski. ${ }^{8}$ There were no values adopted for skinfold thickness. In the United Kingdom the most accessible skinfold values are those of Tanner and Whitehouse. ${ }^{9}$ The data for all these standards were collected between 15 and (in the case of the NCHS values for infants) 59 years ago. These standards are taken from different populations and their use to provide a composite set of multiple anthropometric measurements for an individual subject is of doubtful value.

A set of centiles that allows a comparison of several measurements is that derived from the data of an infant growth study in Cambridge, United Kingdom. ${ }^{10-12}$ The centiles cover weight, length, mid upper arm and head circumference, and triceps and subscapular skinfold thicknesses. They are constructed using the LMS method, which gives smooth centile curves while adjusting for skewness thus permitting skewed data (such as weight or skinfold thickness) to be presented in SD form. ${ }^{13}{ }^{14}$ The method also allows the conversion of SD scores directly into centile values using normal distribution tables. An SD (or Z) score of, for example, an infant's weight at a given age, expresses weight relative to the population mean in the form of a normally distributed variable that has a mean of zero and an SD of one. An SD score can be positive or negative, depending on whether the weight is above or below the mean, and an infant growing along the 50th centile will, on an SD score graph, appear on the horizontal line corresponding to zero. The range of values can be set as required, but the range of normal is conventionally from -2 SD to $+2 \mathrm{SD}$. The use of SD scores is in line with the WHO recommendations ${ }^{715}$ and using these centiles 
it is possible to construct, on one graph, a set of SD scores for multiple measurements, which permit all a child's anthropometric measurements and the factors affecting them to be viewed at once.

In the present study we prospectively followed seven infants through their first year of life to identify those factors affecting their growth such as frequent acute infection-and to assess SD score graphs of multiple measurements as a means of presenting a comprehensive anthropometric picture of individual infants.

\section{Subjects and methods}

The study took place in the village of Keneba, which is in the Kiang West district of The Gambia, West Africa. It is a rural subsistence farming community and has been the site of a nutritional field station for 15 years. It has a population of 1250 and the community has previously been described in detail. ${ }^{16} 17$

Seven sequential births from the village were recruited to a study ${ }^{18}$ of which this formed one part. The study lasted for the first year of the infants' lives.

Measurements were made of body weight, length, mid upper arm circumference, and triceps and subscapular skinfold thickness. These were measured every 14 days when the infants were well and up to six times in the 21 days after the onset of an episode of acute illness. All the measurement were made by one person (MPE). The values were converted into SD scores using the methods described by Cole,$^{13}$ and were then plotted, with all of an individual infants' five sets of values on one graph.
To establish a coefficient of variation for each measurement, repeated short term measurements were made on a group of 10 children. Coefficients of variation were low, being $<0.1 \%$ for weight and head circumference, $2.8 \%$ for mid upper arm circumference, and $6.6 \%$ for skinfold thicknesses.

Illnesses were recorded and treated at the daily, open access, medical clinic held in the village. Diagnoses were made by either of the resident clinicians according to predetermined criteria. ${ }^{18}$ The infants did not attend any other medical service. The illnesses fell into 11 diagnostic groups and for the purposes of the regression analysis each was represented by a two letter code, for instance pneumonia was coded as RP and diarrhoea as DU.

The effect of infection on weight gain was calculated by regression analysis using the Genstat 5 statistical language. Weight gain was calculated, in $\mathrm{g} /$ day, as the difference between successive weights divided by the time interval in days. Individual weights were coded in two ways. Absence of illness was coded as 'well' and a weight measured during an episode of illness was coded by a single diagnosis with time from onset. Thus weights measured on the third, seventh, 10th, and 13th days of an episode of pneumonia were coded as RP03, RP07, RP10, and RP13. Well measurements were coded as WE00. Using five days as the duration of an illness, binary independent variables were constructed for each illness category to indicate whether or not they were present during a time interval. Measurements were also coded by stage of illness as acutely unwell (defined clinically), convalescent (14 days after being acutely unwell), and well.

The study was approved by the joint Medical Research Council and Gambian government ethics committee.

Table Number of episodes of illness for each infant. Total number of days that the infant was ill is shown in parentheses

\begin{tabular}{|c|c|c|c|c|c|c|c|}
\hline \multirow[t]{2}{*}{ Illness } & \multicolumn{7}{|l|}{ Case No } \\
\hline & 1 & 2 & 3 & 4 & 5 & 6 & 7 \\
\hline Upper respiratory tract infection & $6(31)$ & $1(3)$ & $6(29)$ & $1(6)$ & $4(24)$ & $2(11)$ & $3(24)$ \\
\hline Tonsillitis & $1(5)$ & 0 & $1(6)$ & 0 & $2(7)$ & 0 & 0 \\
\hline Otitis media & $2(11)$ & $8(50)$ & $2(8)$ & 0 & $2(11)$ & $6(35)$ & $1(5)$ \\
\hline Pneumonia & $2(9)$ & 0 & 0 & 0 & $2(9)$ & 0 & $1(3)$ \\
\hline Diarrhoea alone & $3(17)$ & $2(18)$ & $7(39)$ & $1(7)$ & 0 & $2(17)$ & $1(12)$ \\
\hline Diarrhoea and vomiting & 0 & $1(4)$ & $1(11)$ & $1(4)$ & $1(5)$ & $1(16)$ & $1(5)$ \\
\hline Vomiting alone & 0 & 0 & 0 & 0 & 0 & 0 & $1(6)$ \\
\hline Malaria & $1(3)$ & 0 & $1(3)$ & 0 & 0 & 0 & 0 \\
\hline Abscess & $1(6)$ & 0 & 0 & 0 & $1(7)$ & 0 & 0 \\
\hline Urinary tract infection & 0 & 0 & 0 & 0 & $1(6)$ & 0 & 0 \\
\hline Fever & $2(9)$ & 0 & $3(17)$ & $1(7)$ & $4(17)$ & $1(5)$ & 0 \\
\hline All illnesses & $18(91)$ & $12(75)$ & $21(113)$ & $4(24)$ & $17(86)$ & $12(84)$ & $8(55)$ \\
\hline
\end{tabular}




\section{Results}

The illnesses from which the infants suffered were divided into 11 diagnostic groups (table). These patterns of morbidity, which are extreme, produced a mean (SD) period of acute illness of 75 (29) days/infant. The mean duration of an episode of illness was $5 \cdot 7(2 \cdot 4)$ days.

The infants had all five anthropometric measurements made on a mean of 30 (6) occasions, with weight alone being measured on a further 6 (2) occasions. The mean interval between weights used for the calculation of weight gain was 10 (7) days.

The effects of infection calculated by regression analysis were significant for three illnesses: diarrhoea and vomiting, pneumonia, and diarrhoea.
Falls in weight gain were respectively: 33 g/day $(p<0.01), 32 \mathrm{~g} /$ day $(\mathrm{p}<0.01)$, and $34 \mathrm{~g} /$ day $(p<0.05)$. Despite the significance of the difference from when they were well, they were not significantly different from one another. The growth rate increments for convalescence and 'well', expressed as positive increments compared with when ill, were $20 \mathrm{~g} /$ day $(\mathrm{p}<0.001)$ and $16 \mathrm{~g} /$ day $(p<0.01)$, respectively. Again, despite their significant differences from when ill, they were not significantly different from each other.

The SD score graphs for the individual infants are shown in figs 1-7. The effect of illness on growth is clearly seen in the graphs, as with case 1 at 30 weeks or case 6 at 39 weeks. The effects of infection are reflected in all measurements, even length. With

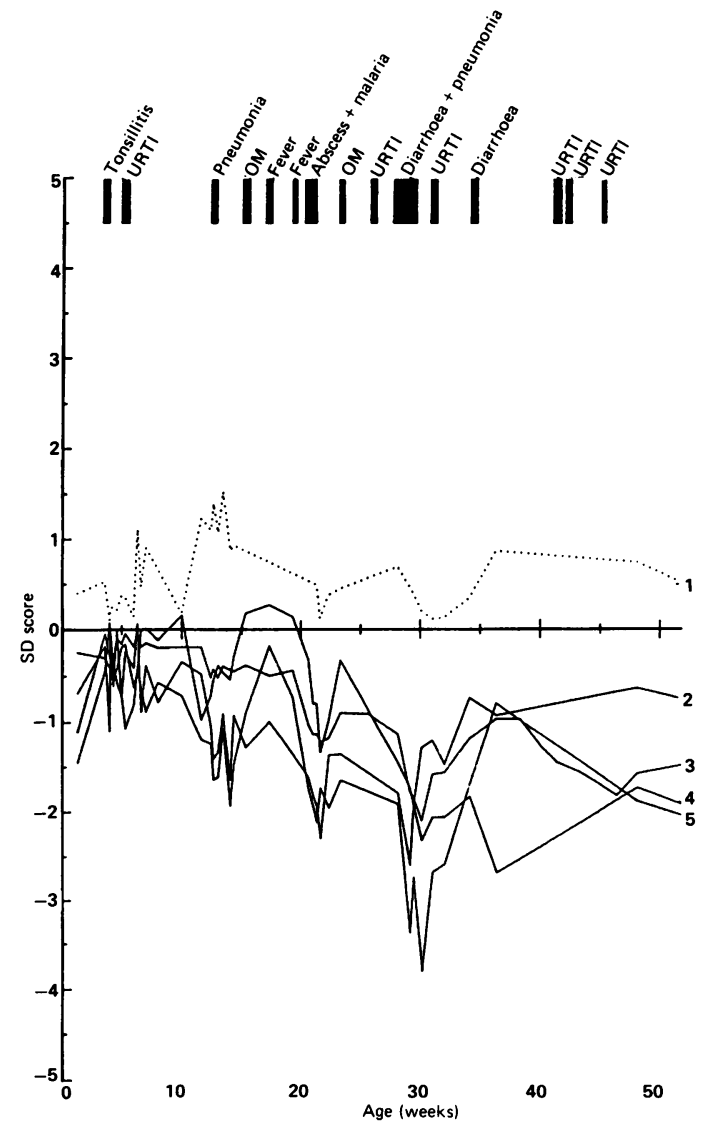

Fig $1 S D$ scores for case 1. OM=otitis media, URT1 $1=$ upper respiratory tract infection; $1=$ length, $2=$ subscapular skinfold thickness, $3=$ weight, $4=$ triceps skinfold thickness, and 5=mid upper arm circumference.

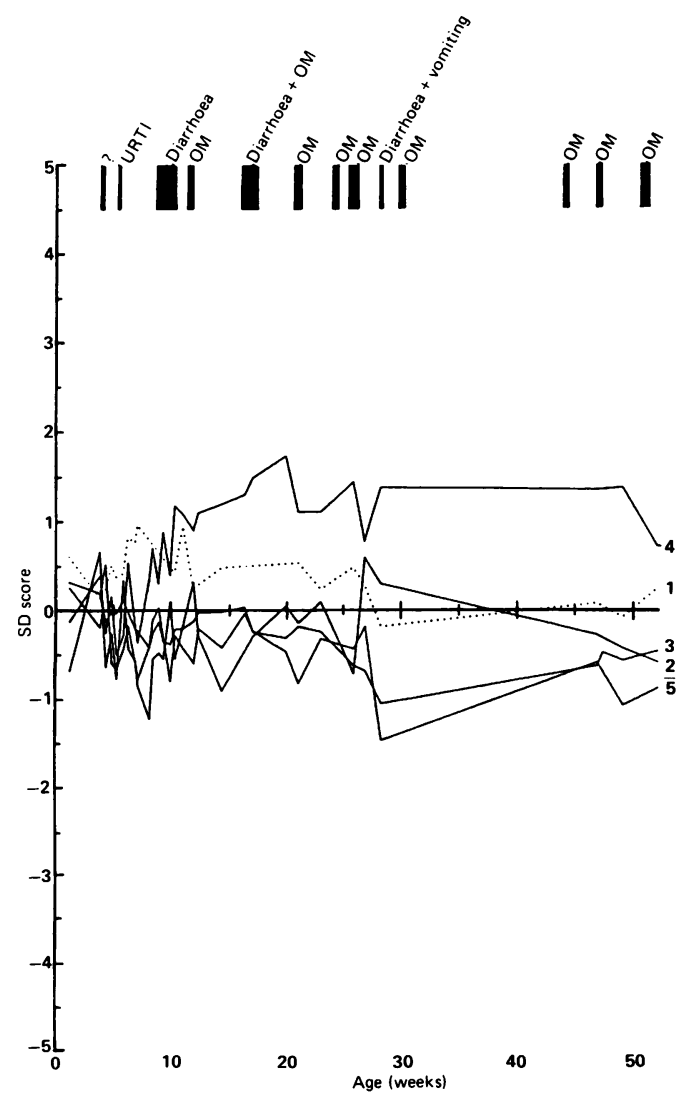

Fig $2 S D$ scores for case 2. OM=otitis media, $U R T 1=$ upper respiratory tract infection; $1=$ length, $2=$ subscapular skinfold thickness, $3=$ weight, $4=$ triceps skinfold thickness, and $5=$ mid upper arm circumference. 
the exception of length and mid upper arm circumference all the measurements are significantly correlated with each other $(p<0.001)$. It is noticeable that the illnesses producing the largest deviations are those identified by regression analysis as causing significant falls in weight gain. With the exception of case 5, growth in length is maintained while the other measurements, particularly weight and mid upper arm circumference, fall consistently, showing that the infants are wasting. Case 5 shows a degree of stunting. With the exception of cases 2 and 3 , the graphs also show that infection produces modulations on an underlying trend. There is an initial variable rise (pronounced in cases 5 and 7) with a universal subsequent fall with most of the values finishing up at -1.5 to -2 SD.

\section{Discussion}

The results of this study confirm the growth faltering

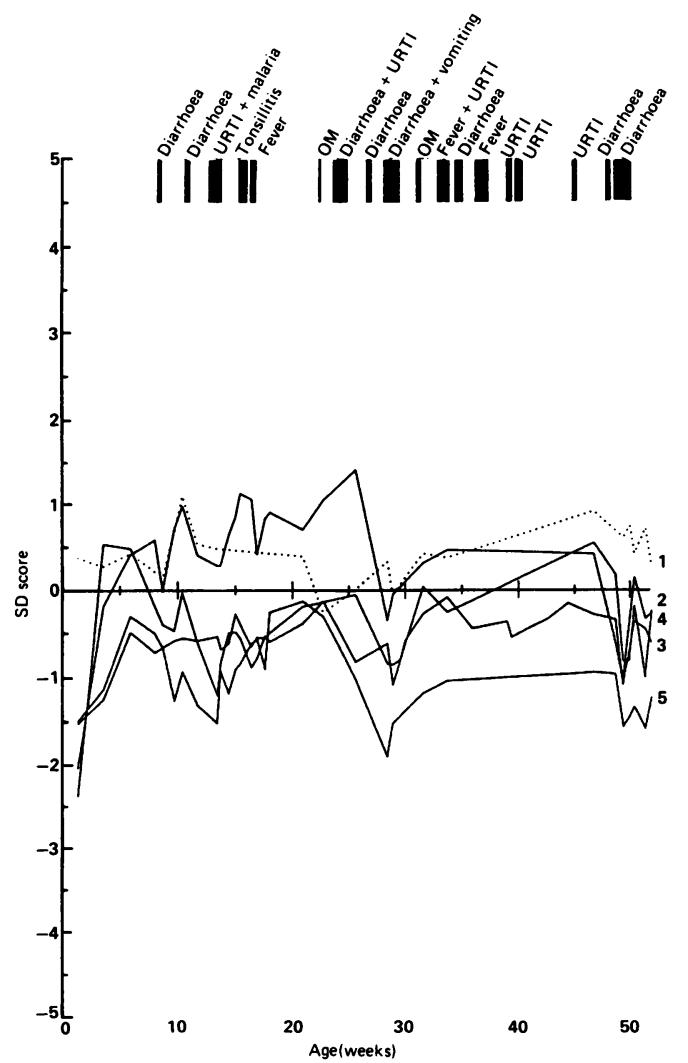

Fig $3 S D$ scores for case 3. OM=otitis media, $U R T 1=$ upper respiratory tract infection; $1=$ length, $2=$ subscapular skinfold thickness, $3=$ weight, $4=$ triceps skinfold thickness, and $5=$ mid upper arm circumference.

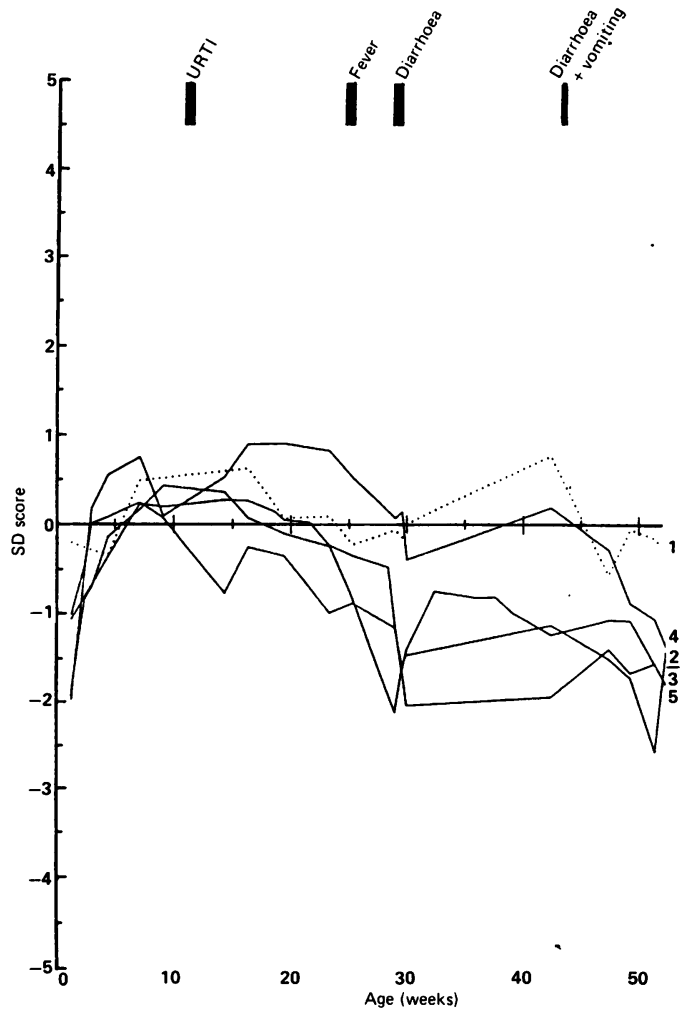

Fig $4 S D$ scores for case 4. URTI= upper respiratory tract infection; $1=$ length, $2=$ subscapular skinfold thickness, 3=weight, $4=$ triceps skinfold thickness, and 5=mid upper arm circumference.

effects of gastroenteritic and lower respiratory tract disease in infants in third world countries. This is shown qualitatively for individual infants by the multiple measurement standard deviation score graphs, and quantitatively for all infants by the regression analysis.

The multiple measurement SD score graphs allow the whole anthropometric progress of an infant to be viewed at once. The significant effects of gastroenteritis and pneumonia are easily seen on the graphs, as are the growth faltering effects of other episodes of illness.

It is important to understand the justification for using the Cambridge growth curves in a West African population. The Cambridge data set has all its measurements drawn from the same infants, giving it a cohesion not present in other data sets and allowing 'across measurement' comparisons to be soundly based. The LMS method provides (uniquely) SD scores for skewed variables like 


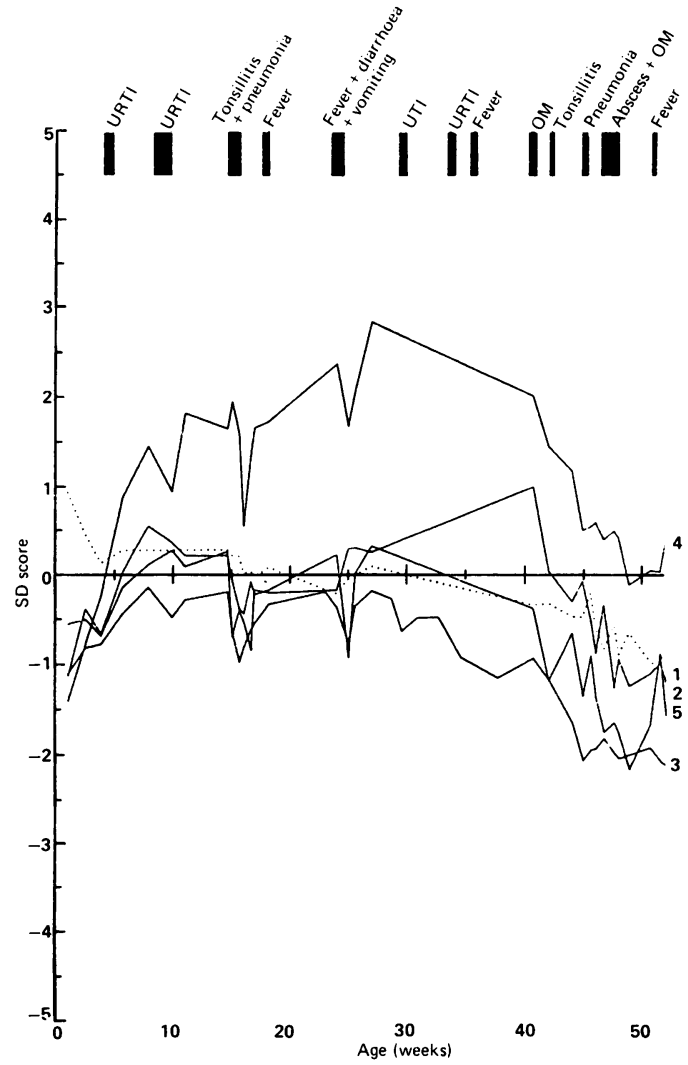

Fig 5 SD scores for case 5. OM=otitis media,

$U R T I=$ upper respiratory tract infection, $U T I=$ urinary tract infection; $1=$ length, 2 =subscapular skinfold thickness, $3=$ weight, $4=$ triceps skinfold thickness, and 5=mid upper arm circumference.

weight and skinfold thickness, and it is this that allows the construction of the SD score graphs. Furthermore, the growth curves are based upon infants who were fed in the manner currently recommended by the DHSS. ${ }^{19}$ This permits prolonged breast feeding and more closely resembles the feeding patterns of the Keneba infants. Given that infant feeding patterns affect growth it is sensible to use growth curves that are as appropriate as possible in this respect. ${ }^{11}$

In all the infants the graphs identify not only the effects of illness but also a steady fall in the SD score for weight from about 15 weeks of age. As all the infants except case 5 maintained their growth in length, this represents wasting. With his steady fall off in both weight and length, case 5 shows evidence of stunting, a feature of growth that is, in Keneba, more normally seen after infancy.
The size of the weight deficit over infancy is calculable. Using the figures for 'convalescence/ well' it is possible to calculate the mean weight deficit in the seven infants caused by acute infection, and thus the weight deficit from other causes. The infants were acutely unwell for $20 \%$ of the time, convalescent for $34 \%$ of the time, and well for $46 \%$ of the time. The deficit for acute illness is: 16 $\mathrm{g} /$ day $\times 0 \cdot 2=3 \cdot 2 \mathrm{~g} /$ day. Had the infants never been acutely unwell they would never have been convalescent so this figure of $3.2 \mathrm{~g} /$ day has to have subtracted from it the difference between being well and being convalescent: $(20-16) \times 0 \cdot 34=1.4 \mathrm{~g} /$ day. This produces an overall figure of $1.8 \mathrm{~g} /$ day weight deficit as a result of infection, which produces a total of almost $700 \mathrm{~g}$ over the first year of life.

The mean weight deficit at 12 months, measured from the Cambridge growth curve 50th centile for

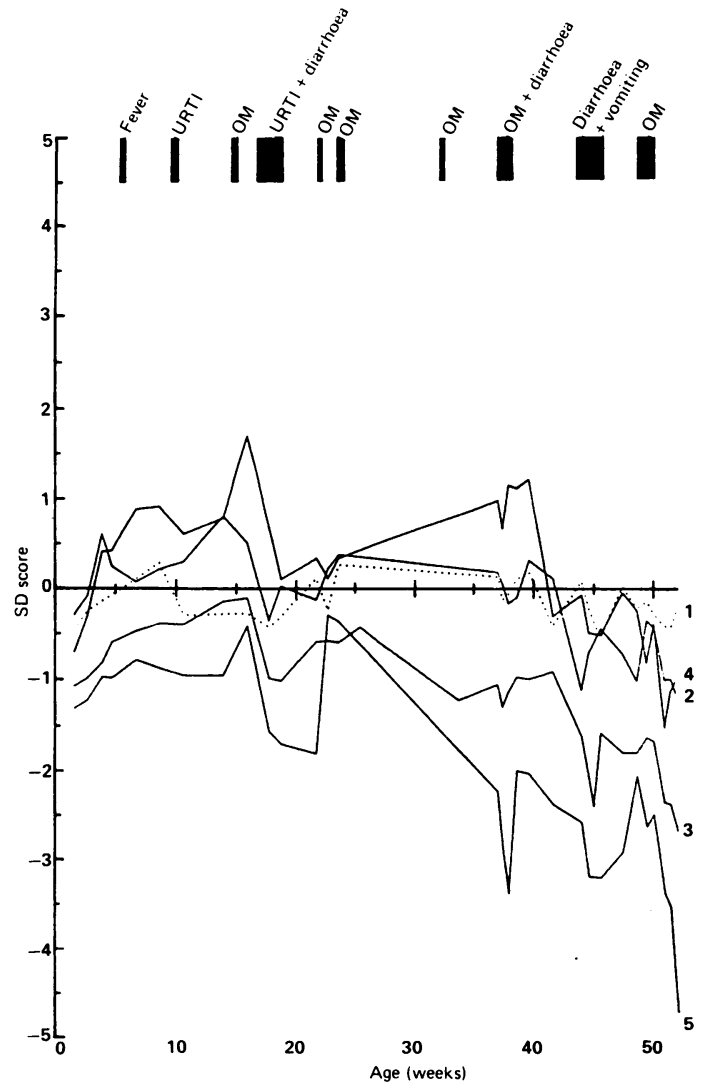

Fig $6 S D$ scores for case 6. OM=otitis media,

$U R T 1=$ upper respiratory tract infection; $l=$ length,

$2=$ subscapular skinfold thickness, $3=$ weight, $4=$ triceps skinfold thickness, and 5=mid upper arm circumference. 


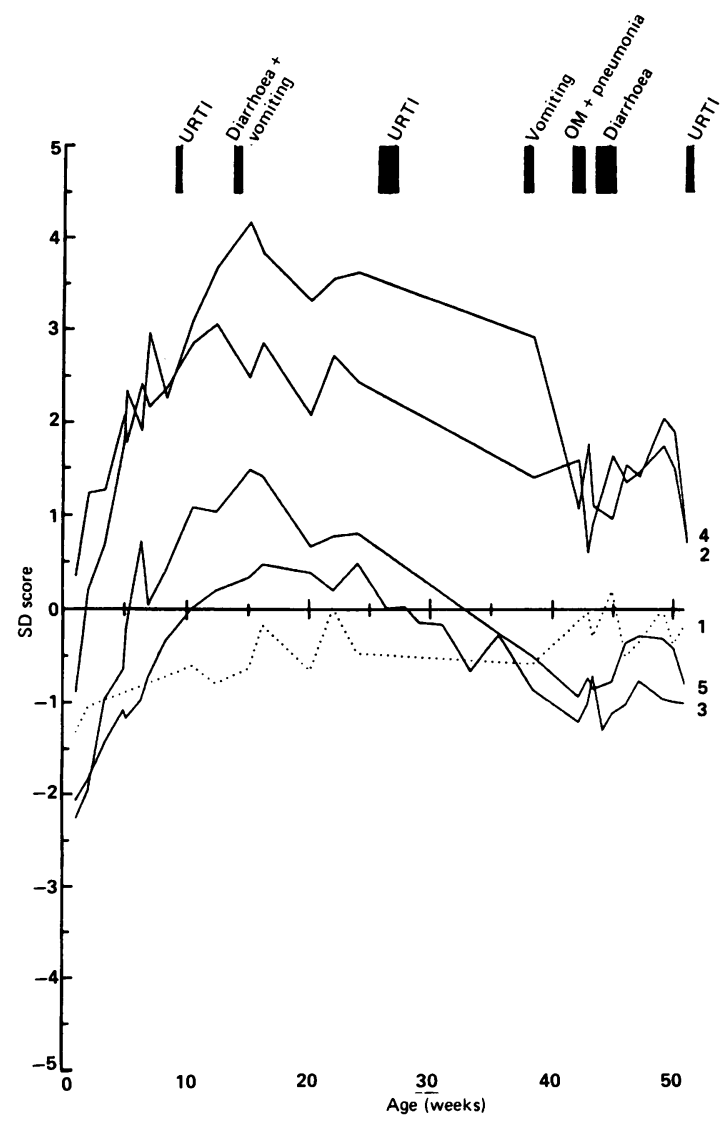

Fig $7 S D$ scores for case 7. OM=otitis media, $U R T 1=$ upper respiratory tract infection; $1=$ length, $2=$ subscapular skinfold thickness, $3=$ weight, $4=$ triceps skinfold thickness, and $5=$ mid upper arm circumference.

weight, was $1200 \mathrm{~g}$. The $700 \mathrm{~g}$ deficit calculable as a result of infection represents $58 \%$ of this total leaving $42 \%(500 \mathrm{~g})$ of the weight deficit resulting from other causes. This figure of $500 \mathrm{~g}$ corresponds to the slow fall in the SD score of weight seen in the graphs.

A similar picture of weight loss was found by Rowland et al working in Bakau, an urban community on The Gambia's Atlantic coast. ${ }^{5}$ Using as their standard the NCHS growth curves ${ }^{6}$ they found an illness related weight deficit of $900 \mathrm{~g}$ at 12 months, broadly similar to the $700 \mathrm{~g}$ that we found. Their total weight deficit was, however, only a further $300 \dot{\mathrm{g}}$, whereas the corresponding Keneba value, having allowed for the $400 \mathrm{~g}$ difference between the means of the two standards, is a further $900 \mathrm{~g}$; this is three times the Bakau figure.
When comparing Keneba and Bakau, Tomkins et al showed seasonal swings in growth rates in both communities. ${ }^{20}$ These swings were larger in Keneba where seasonal food shortage, as opposed to Bakau's year round availability of food, was thought to account for much of the difference in growth performance between the two communities. Although food intake was not measured in this study, previous work in Keneba has shown infant energy intake to be low and an underlying deficiency in energy intake provides a rational explanation for the steady wasting seen in the SD score graphs. ${ }^{21}$

The illnesses producing an impact on growth are similar to those identified by previous authors. Diagnostic criteria vary, but the diagnoses of diarrhoea, and diarrhoea and vomiting, in this study can be equated with diarrhoea or gastroenteritis from other studies. ${ }^{13-5}$ Previous work in Keneba identified diarrhoeal disease as an important cause of weight loss with a fall in weight gain of $25 \mathrm{~g} /$ day. ${ }^{3}$ This is similar to the figure of $34 \mathrm{~g} /$ day found in this study and shows that the cost in terms of weight gain associated with infant diarrhoea in this rural community has unfortunately not changed over the last 10 years. It is also worth noting that the study of Rowland $e t a l^{5}$ and this study both identified lower respiratory tract infection as an important cause of failure of growth.

SD score graphs provide a powerful method of identifying and highlighting problems with growth resulting from, in this case, the effects of infection and undernutrition. This has not previously been possible because of the lack of an adequate multimeasurement standard. These effects are statistically calculable within the group, but when considering an individual subject the use of SD score graphs permits both the time scale and the accurate progress of an individual subject to be clearly seen. Moreover the curves permit simultaneous comparison across five different anthropometric measurements and the demonstration of the effects of those illnesses that cause growth faltering in an individual subject but do not achieve significance within the group. Although applied here to the acute and chronic problems of infants in the third world, these graphs could equally well be used to record the anthropometric progress of any child suffering from any acute (for example, infective) or chronic (for example, coeliac disease) condition.

We are grateful to the families and particularly the mothers of our seven subjects who were immensely helpful and understanding during the course of the study. We thank M Jarjue for technical assistance. We also acknowledge the support of the Medical Research Council Laboratories at Fajara. and The Gambian Government. 


\section{References}

1 Condon-Paoloni D, Cravioto J, Johnston FE, De Licardie ER. Scholl TO. Morbidity and growth of infants and young children in a rural Mexican village. Am J Public Health 1977;67:651-6.

2 Mata LJ, Urrutia JJ, Abertazzi C, Pellecer O, Arellano E. Influence of recurrent infections on nutrition and growth of children in Guatemala. Am J Clin Nutr 1972;25:1267-75.

3 Rowland MGM, Cole TJ. Whitehead RG. A quantitative study into the role of infection in determining nutritional status in Gambian village children. Br J Nutr 1977;37:441-50.

4 Cole TJ, Parkin JM. Infection and its effects on the growth of young children: a comparison of The Gambia and Uganda. Trans $R$ Soc Trop Med Hyg 1977;71:196-8.

5 Rowland MGM, Goh Rowland SGJ, Cole TJ. The impact of infection on the growth of children from 0 to 2 years in an urban West African community. Am J Clin Nutr 1988;47:134-8.

6 National Center For Health Statistics. NCHS growth curves for children, birth-18 years. Washington: US Department of Health Education and Welfare, 1977.

7 Waterlow JC, Buzina R, Keller W, Lane JM, Nichaman MZ, Tanner JM. The presentation and use of height and weight data for comparing the nutritional status of children under the age of 10 years. Bull WHO 1977;55:489-98.

* Wolanski N. Standards for arm circumference. Quoted in: Jelliffe DB. The assessment of nutritional status in the community. Geneva: World Health Organisation, 1966. (WHO Monograph Series No 53.)

9 Tanner JM, Whitehouse RH. Revised standards for triceps and subscapular skinfolds in British children. Arch Dis Child 1975;50:142-5.

10 Whitehead RG, Paul AA. Growth charts and the assessment of infant feeding practices in the western world and in developing countries. Early Hum Dev 1984;9:187-207.

1 Whitehead RG, Paul AA, Ahmed EA. Weaning practices in the United Kingdom and variations in anthropometric development. Acta Paediatr Scand 1986;323(suppl):14-23.

12 Whitehead RG, Paul AA. Ahmed EA. DHSS present day infant feeding practice and its influence on infant growth. In: Tanner JM. Preece MA, eds. The physiology of growth.
Proceedings of the society for the study of human biology. Symposium No 29. Cambridge: Cambridge University Press. 1989.

13 Cole TJ. Fitting smoothed centile curves to reference data. Journal of the Royal Statistical Society (Series A) 1988;151: 385-418.

14 Cole TJ, Paul AA, Eccles MP, Whitehead RG. The use of a multiple growth standard to highlight the effects of diet and infection on growth. In: Tanner JM, ed. Auxology '88: perspectives in the science of growth and development. London: Smith, Gordon, 1989.

15 World Health Organisation. Measuring change in nutritional status. Geneva: World Health Organisation, 1983.

16 Thompson B. Marriage, childbirth and early childhood in a Gambian village: a socio-medical study. Aberdeen: University of Aberdeen, 1965. 353 pp. (PhD thesis.)

17 Lamb WH. A prospective study of psychomotor development in rural West African (Gambian) infants. Newcastle: University of Newcastle upon Tyne, 1987. 299 pp. (MD thesis.)

18 Eccles M. A prospective study of the effects of frequent infection on the energy metabolism of Gambian infants. Newcastle: University of Newcastle upon Tyne, 1988. 235 pp. (MD thesis.)

19 Report of a Working Party of the Panel on Child Nutrition, Committee on Medical Aspects of Food Policy. Department of Health and Social Security. Report on health and social subjects 20: present day practice in infant feeding. 1980. London: HMSO, 1983.

20) Tomkins AM, Dunn DT, Hayes RJ, Bradley AK. Seasonal variations in the nutritional status of urban Gambian children. Br J Nutr 1986;56:533-43.

21 Whitehead RG, Rowland MGM, Hutton MA, Prentice AM, Muller EM, Paul AA. Factors influencing lactation performance in rural Gambian mothers. Lancet 1978;ii:178-81.

Correspondence to Dr MP Eccles, Prospect House Medical Group, Prospect House, Prospect Place, Newcastle Upon Tyne, NE4 6QD.

Accepted 1 June 1989 